\title{
LETTER
}

\section{A little less saturation?}

\author{
Jack JM Ligtenberg*1, Renate Stolmeijer', Josien J Broekema', Jan C ter Maaten and Jan G Zijlstra² \\ See related viewpoint by Cornet et al., http://ccforum.com/content/17/2/313
}

In the previous issue of Critical Care, Alexander Cornet and colleagues reasoned quite convincingly that the liberal use of supplemental oxygen, which is common in the resuscitation of critically ill patients, may be detrimental instead of beneficial [1].

The Surviving Sepsis Campaign guidelines do not give specific recommendations about the amount of oxygen to be administered for patients with severe sepsis or septic shock; instead, they advise one to maintain peripheral oxygen saturation between 88 and 95\% [2]. Most prehospital and emergency department (ED) sepsis protocols administer $15 \mathrm{l}$ oxygen/minute with a nonrebreather mask or 101 oxygen/minute with a VentiMask (Intersurgical Ltd, Wokingham, Berkshire, UK), resulting in an inspired oxygen fraction $\left(\mathrm{FiO}_{2}\right)$ of respectively \pm 0.6 to 0.8 and 0.4 .

Although evidence is accumulating that hyperoxia is disadvantageous in more instances than only after cardiac arrest [3], this topic has not been investigated in sepsis patients. We decided to reduce the $\mathrm{FiO}_{2}$ in our ED sepsis protocol from $0.6-0.8$ to 0.4 and subsequently evaluated the incidence of hyperoxia and hypoxia in sepsis patients admitted to the ED [4]. Only 7\% of all patients showed hypoxia and needed a nonrebreather mask with $15 \mathrm{l}$ oxygen/minute; most of these patients had a positive history for pulmonary diseases. Of the patients treated with a $\mathrm{FiO}_{2}$ of $0.4,64 \%$ still showed hyperoxia (defined as $\mathrm{PaO}_{2}>13.5 \mathrm{kPa}$ ). Decreasing the $\mathrm{FiO}_{2}$ therefore seems justified and appears to be safe; the small portion of patients with hypoxia can be identified within 5 minutes and oxygen can be increased immediately.
We agree with Cornet and colleagues that oxygen should be titrated to normoxia (with the use of the pointof-care blood gas analyser), also with oxygen use for sepsis patients admitted to the ED. However, serious action will be required to abolish the widespread attitude that one cannot get enough oxygen.

\section{Abbreviations}

$\mathrm{ED}$, emergency department; $\mathrm{FiO}_{2}$, inspired oxygen fraction.

\section{Author details}

'Emergency Department, University Medical Center Groningen, PO Box 30001, 9700RB Groningen, The Netherlands. ${ }^{2}$ Department of Critical Care, University Medical Center Groningen, PO Box 30001, 9700RB Groningen, The Netherlands.

\section{Published: 19 June 2013}

\section{References}

1. Cornet AD, Kooter AJ, Peters MJL, Smulders YM: The potential harm of oxygen therapy in medical emergencies. Crit Care 2013, 17:313.

2. Dellinger RP, Levy MM, Rhodes A, Annane D, Gerlach H, Opal SM, Sevransky JE, Sprung CL, Douglas IS, Jaeschke R, Osborn TM, Nunnally ME, Townsend SR, Reinhart K, Kleinpell RM, Angus DC, Deutschman CS, Machado FR, Rubenfeld GD, Webb SA, Beale RJ, Vincent JL, Moreno R; Surviving Sepsis Campaign Guidelines Committee including the Pediatric Subgroup: Surviving Sepsis Campaign: international guidelines for management of severe sepsis and septic shock: 2012. Crit Care Med 2013, 41:580-637.

3. O'Driscoll R: Emergency oxygen use. BMJ 2012, 345:e6856.

4. Stolmeijer R, ter Maaten JC, Zijlstra JG, Ligtenberg JJM: Oxygen therapy for sepsis patients in the emergency department; a little less? Eur J Emerg Med 2013. [Epub ahead of print]

doi:10.1186/cc12726

Cite this article as: Ligtenberg JJM, et al:: A little less saturation? Critical Care 2013, 17:439.

\footnotetext{
*Correspondence: j.j.m.ligtenberg@umcg.nl

'Emergency Department, University Medical Center Groningen, PO Box 30001 ,

9700RB Groningen, The Netherlands

Full list of author information is available at the end of the article
} 